\title{
A Protein-Reinforced Adhesive Composite
}

\section{Electrolyte}

\author{
Xiaolin Wang, Xuewei Fu, Yu Wang* and Weihong Zhong*
}

\begin{abstract}
Adhesive composite electrolytes are of great interest due to the potential in achieving a good balance among electrochemical, mechanical and interfacial properties. However, in composite electrolytes, the fillers are usually rigid inorganic nanoparticles with limited functional groups contributing to mechanical properties and/or adhesion properties. In this study, abundant proteins are employed as unique additive for fabricating composite electrolytes with notable improvement in not only mechanical strength, but also adhesion properties. It is found that the introduced protein forms uniform nanoparticles in the final composite electrolyte. The influence of the protein nanofiller on the electrolyte properties (mechanical, ionic conductivity and adhesion properties) is investigated. The results indicate that proteins, particularly gelatin protein, can notably improve not only the mechanical properties (modulus and elasticity), but also the adhesion properties, while the high ionic conductivity of the electrolyte matrix is maintained.
\end{abstract}


Benefited from the above significant properties of the composite electrolyte, the electrochemical performance of a half-cell with the gelatin-reinforced composite electrolyte is notably improved as compared with the cell with conventional liquid electrolyte. This study indicates that natural proteins can be a promising functional bio-filler for composite electrolytes.

Keywords: Adhesive electrolyte, natural protein, organic filler, mechanical properties, adhesion, energy storage device 


\section{Introduction}

With the development of energy storage devices, there is an increasing demand for advanced battery systems that have high energy/power densities, excellent safety and device flexibility, such as lithium/sodium ion batteries.[1-5] As one of the primary components of batteries, electrolyte plays a critical role in the electrochemical and mechanical performance of the batteries. High ionic conductivity, appropriate mechanical properties, strong adhesion leading to stable/good electrolyte/electrode contact, good thermal and electrochemical stabilities are crucial properties for advanced non-liquid electrolyte materials.[6,7] Combining these significant properties, including electrochemistry, mechanics, surface/interface, and thermal stability, in single-phase materials has been extremely challenging.[6]

In general, organic liquid electrolytes (OLEs) widely used today possess the highest ionic conductivity above $10^{-3} \mathrm{~S} / \mathrm{cm}$ at room temperature and superior interfacial behavior (good/stable contact) with electrodes; however, they are responsible for the well-known safety issues, such as leakage, thermal runaway at high temperature, and poor mechanical properties.[8-10] Solid polymer electrolytes are believed to be a promising candidate mainly because of their good mechanical properties and excellent safety;[6] however, the low ionic conductivity which is typically in the range of $10^{-8} \sim 10^{-5} \mathrm{~S} / \mathrm{cm}$ at room temperature, and inferior interfacial properties with electrode particles as compared with OLEs are preventing them from practical applications.[11] Another type of solid electrolyte, that is, inorganic solid electrolytes, is also of great interest recently due to the high ionic conductivity and high modulus.[6]However, these inorganic solid electrolytes show a poor processability and brittleness which block them from broad application. 
As a combination of solid polymer electrolytes and OLEs, gel electrolytes are believed to be one of the most promising candidates with the potential of simultaneously achieving the significant electrolyte properties.[12-14] However, the addition of liquid component in a gel electrolyte will inevitably deteriorate the mechanical properties.[6,25] As a result, achieving a good balance between ionic conductivity and mechanical properties has been one of the primary tasks for high performance gel electrolytes.[15,16] Currently, there are several strategies for fabrication of high-performance gel electrolytes. The first one is the construction of inter-penetrating continuous phases, in which the rigid one is for good mechanical properties and the soft one is for high ion-conductivity. This strategy includes the studies on gel electrolytes based on copolymers,[17] polymer blends[18] and so on. The second strategy is to crosslink the polymer matrix. For instance, one can crosslink the gel electrolytes by various curing techniques, such as UV-curing [25, 28-30] thermally curing [19, 20] or self-curing[21]. Another significant strategy is to reinforce the gel matrix with various nanofillers and polymer nanocomposite gel electrolytes are achieved.[22-24, 31] For example, nanoparticles, such as $\mathrm{SiO}_{2}$ [26] $\mathrm{Al}_{2} \mathrm{O}_{3}$ [22] and $\mathrm{TiO}_{2}$ [27] etc., have been introduced into the matrix to reinforce the nanocomposite gel electrolytes.

Although significant progress has been made on composite gel electrolytes, the filler phase is limited to traditional polymers and/or inorganic particles. For the fillers, the contribution to the interfaces, including the interfaces inside the composite itself and the ones with other substrates (such as electrode particles and current collectors in a battery), should be taken into consideration for the development of a high-performance composite electrolyte. Proteins, wellknown by their diversity in functions and structures, are of great interest at this point.[32] Based on our previous studies on an adhesive composite electrolyte, the gum-like electrolyte,[3, 24] 
animal-derived (gelatin) and soy protein isolate (SPI) have been employed in this study as functional bio-fillers for adhesive composite electrolytes. The in-built functional groups on the protein chain can potentially improve the adhesion properties as well as mechanical properties of the resultant composites, which will be demonstrated in this study.

\section{Experimental}

Materials. (a) For electrolyte fabrication studies. The materials include ultra-high molecular weight poly (ethylene oxide) (UHMWPEO, $\mathrm{M}_{\mathrm{w}}=4 \times 10^{6} \mathrm{~g} / \mathrm{mol}$, Sigma Aldrich), lithium salt $\left(\mathrm{LiClO}_{4}\right.$, Sigma Aldrich), propylene carbonate, paraffin wax, surfactant (sorbitan monostearate), gelatin (gel strength 300, Type A, Sigma Aldrich) and SPI (90\% purity, Archer Daniels Midland Co.). (b) For electrochemical performance studies. The materials include cathode particles ( $\mathrm{LiCoO}_{2}$, MTI corp.), carbon black (CB, MTI corp.), polyvinylidene fluoride (PVDF, $\mathrm{Mw}=$ 530,000 g/mol, Sigma Aldrich), commercial separator (Celgard) and liquid electrolyte (1 mol/L $\mathrm{LiPF}_{6}$ in EC/DMC, Sigma Aldrich).

Sample Preparation. (a) For composite electrolyte studies. The adhesive composite electrolytes were prepared as follows. On the first step, PEO and gelatin solutions were separately prepared in deionized water. A certain amount of $\mathrm{LiClO}_{4}$ was also dissolved in the PEO solution according to a weight ratio PEO : $\mathrm{LiClO}_{4}=3.3: 1$, which means the mol ratio of oxygen atom of $\mathrm{PEO}$ to $\mathrm{Li}^{+}$is $8: 1$. On the second step, $\mathrm{PEO} / \mathrm{LiClO}_{4}$ solution and gelatin solution were mixed with different weight ratios. The resulting mixture was cast at room temperature and dried in open air for 1 day followed by further drying in vacuum oven for $24 \mathrm{~h}$ at $15 \mathrm{kPa}$ at $50{ }^{\circ} \mathrm{C}$. On the third step, the plasticizer, that is, a liquid electrolyte $\left(1 \mathrm{~mol} / \mathrm{L} \mathrm{LiClO}_{4}\right.$ in $\left.\mathrm{PC}\right)$ was sprayed onto the dried composite electrolyte film and adhesive composite electrolytes were prepared. For SPI 
composite samples, SPI powder was first thermally denatured at $95{ }^{\circ} \mathrm{C}$ and then, the denatured SPI suspension was mixed with $\mathrm{PEO} / \mathrm{LiClO}_{4}$ solution. Other procedures are similar to these for the gelatin composite samples. For comparison, regular filler (eg. wax particles with surfactant sorbitan monostearate on the surface) has been employed. The wax particles were prepared by emulsion technique with $10 \mathrm{wt} \%$ surfactant. For all the types of composite electrolytes, there are two groups of samples. For the first one, the overall loading of plasticizer, that is, liquid electrolyte, is fixed by $50 \mathrm{wt} \%$ in the resultant composite electrolytes while varying the ratio between the filler and $\mathrm{PEO} / \mathrm{LiClO}_{4}$. For the second one, the weight ratio between the plasticizer and $\mathrm{PEO} / \mathrm{LiClO}_{4}$ is fixed by $1: 1$ and, the loading of filler in the final composite electrolyte was adjusted accordingly. (b) For electrochemical performance studies. To fabricate electrode, cathode particles $\left(\mathrm{LiCoO}_{2}\right)$ and carbon black was first mixed by mortar, then PVDF solution (5 $\mathrm{wt} \%$ in NMP) was added and grinded with the solid particles until a homogeneous electrode slurry was obtained. The electrode slurry was cast on Al-foil and dried at $60{ }^{\circ} \mathrm{C}$ in fume hood. Before it was transferred into glovebox, the solid electrode was further dried in vacuum oven (70 ${ }^{\circ} \mathrm{C}, 10 \mathrm{kPa}$ ) for ca. 12 hours. To assemble a $\mathrm{Li} /$ gelatin-CE/LiCoO 2 half-cell, the dried solid gelatin composite electrolyte (Gelatin-CE) film was plasticized by liquid electrolyte and then used as electrolyte and separator. Due to the good adhesion properties and mechanical conformability, the plasticized electrolyte film formed an adhesive coating on the cathode surface, then the anode (Li-metal) was attached onto the electrolyte surface. The Li/gelatin$\mathrm{CE} / \mathrm{LiCoO}_{2}$ sandwich was then sealed into a coin cell. At the same time, conventional half-cell, that is, $\mathrm{Li} /$ liquid electrolyte-separator/ $\mathrm{LiCoO}_{2}$, was also assembled for comparison study.

Characterizations. (1) Structure and morphology: Scanning Electron Microscopy (SEM) and Polar Light Microscopy (Olympus BX51) were used to characterize the morphology of the 
adhesive composite electrolytes. The particle dispersion quality was also investigated by SEM and PLM. (2) Properties. a) Ionic conductivity. The room temperature ionic conductivity was measured via AC impedance spectroscopy (Universal Dielectric Spectrometer BDS 20). The frequency range was chosen from $1 \mathrm{~Hz}$ to $3 \times 10^{6} \mathrm{~Hz}$. The electrolyte samples were placed between two gold electrodes with a diameter of $2 \mathrm{~cm}$ and a thickness of $2 \mathrm{~mm}$. The input testing voltage was $1 \mathrm{~V}$. All measurements were repeated at least 3 times. b) Mechanical properties. The modulus was characterized by a rheometer (Discovery HR-2, TA) via frequency sweep from 0.5 $\mathrm{Hz}$ to $10 \mathrm{~Hz}$ at room temperature. For all frequency sweep, the strain was controlled with $1 \%$, which is in the range of linear viscoelastic region of the material. For comparison, the modulus at $1 \mathrm{~Hz}$ is used for all the samples. Each sample was tested at least 3 times. For elasticity measurement, a creep and recovery testing via the rheometer was carried out. The cut-off strain for the creep step was controlled to be $100 \%$ which is finished in ca. 15 s. Followed step is the strain recovery for $30 \mathrm{~s}$. The elasticity was then calculated by $\left(\gamma_{0}-\gamma_{30}\right) / \gamma_{0}$, where $\gamma_{0}$ is the total strain achieved in the creep step, $\gamma_{30}$ is the residual strain after $30 \mathrm{~s}$ of recovery. c) Adhesion properties. Adhesion properties were evaluated by peeling off testing. The electrolyte samples were placed between two parallel steel plates with a diameter of $8 \mathrm{~mm}$. A constant extension speed, $1000 \mu \mathrm{m} / \mathrm{s}$, was used to detach the substrate from the sample. The maximum axial force was measured during the detaching process. Based on the maximum axial force, $F_{\max }$, the adhesion strength can be calculated via $\sigma_{a}=F_{\max } / A$, where $\mathrm{A}$ is the contact area between the sample and the substrate. All measurement was carried out at room temperature and repeated at least 5 times. For electrochemical testing, the half-cell was tested by a battery analyzer at a constant current rate $(0.1 \mathrm{C})$ for a certain number of cycles.

\section{Results and Discussion}




\subsection{Rational Design}

As shown in Figure 1 (a), proteins are well-known by their diversity in functional groups (such as $-\mathrm{COOH},-\mathrm{OH},-\mathrm{NH}_{2}$ etc.) due to different types of amino acids. These functional groups and unique assembly structures indicate that proteins could be a unique additive for composite electrolytes as explained below. As illustrated by Figure 1(b), protein may form uniform particles in a highly ion-conductive matrix consisting of UHMWPEO, $\mathrm{LiClO}_{4}$ and liquid electrolyte (LE) ( $1 \mathrm{~mol} / \mathrm{L} \mathrm{LiClO}_{4}$ in Propylene Carbonate). The LE forms pathway for lithium ions conduction and leads to a liquid-level ionic conductivity. At the same time, the introduction of the protein may contribute to mechanical properties and adhesion. In particular, the functional groups and peptide bonds of the protein chains can form strong interactions (e.g. hydrogen bonding) with the PEO chains as shown in Figure 1 (b). As a result, a physical crosslinking network can be formed due to the strong interfacial interactions between the protein particles and PEO matrix. This physical crosslinking network may remarkably improve the mechanical strength as well as elasticity of the composite material. In addition, the functional groups of the protein particles may provide strong adhesion with different substrates and, improve the interfacial properties with electrode particles as illustrated in Figure 1 (c). As a result, high ionic conductivity, good mechanical properties and strong adhesion properties can be simultaneously achieved by the resultant composite electrolyte with protein as functional fillers, which is the target of this study.

\subsection{Structure and morphology}

Figure 2 shows the morphology of the adhesive composite electrolytes. Two types of protein with similar chemical compositions, gelatin and SPI, were studied. For comparison, wax 
particles (see the insert in Figure 2(f)) with much less functional groups on the surface, but similar particle size as compared with the SPI particles was also employed. As shown by the inserts in Figure 2 (a) and (b), gelatin was completely dissolved and a transparent solution was obtained. In comparison, SPI was partially denatured, which leads to a suspension finally. The denatured SPI particles are characterized by the inserted SEM image in Figure 2 (e), which shows that the denatured SPI are very small nanoparticles with size around $30 \mathrm{~nm}$. The wax particles formed a stable emulsion with the help of surfactant as displayed in the insert in Figure 2 (c). These additives finally form particles in the composite electrolytes as shown by Figure 2 (a) - (c)

In specific, the gelatin exists as a type of nanoparticles uniformly distributed in the adhesive matrix as shown by Figure 2 (a). Figure 2 (b) and (c) are SEM images showing the morphology of the adhesive composite electrolyte with SPI and wax particles, respectively. From these SEM images, one can find that the two proteins self-assemble into particles and form a type of filler after mixing with the polymer matrix. It is also noted that there is a significant difference in the particle size. The size of gelatin particles is the smallest $(200-300 \mathrm{~nm})$, followed by wax particles and SPI particles $(1-2 \mu \mathrm{m})$. In addition to the notable difference in particle size, the boundary around the particles is also different. In particular, the phase boundary of gelatin particles is even invisible, indicating strong interactions and good interface with the adhesive matrix. However, as shown in Figure 2 (d) - (f), the phase boundary in the samples with the SPI and wax particles is much clearer than that of gelatin particles, demonstrating weaker interactions between these filler particles and the adhesive matrix. The above difference in particle size and interfacial interactions will have significant influence on mechanical and adhesion properties of the resultant composite electrolytes as will be revealed later. 


\subsection{Ionic conductivity}

The ionic conductivity of the first group of composite electrolytes with constant loading of plasticizer (50 wt\%) is summarized in Figure 3. As shown in Figure 3 (a), (b) and (c), an obvious plateau of the ionic conductivity can be observed in high frequency range for each curve, which represents the DC ionic conductivity of the electrolyte. Based on these curves, the ionic conductivity for these adhesive composite electrolytes with $50 \mathrm{wt} \%$ LE plasticizer is around 1.5 $\times 10^{-3} \mathrm{~S} / \mathrm{cm}$ at room temperature, which is at the level of pure liquid electrolytes with ionic conductivity of $3.6 \times 10^{-3} \mathrm{~S} / \mathrm{cm}$. As shown in Figure $3(\mathrm{~d})$, the loading of filler has little effect on the ionic conductivity in the loading range studied, which is also independent of the type of fillers. The above result can be explained as following. Since the loading of LE plasticizer is fixed and the pathway for lithium ion conduction is mainly controlled by the plasticizer (the liquid electrolyte) in the adhesive electrolyte, the ionic conductivity won't change notably with the type and loading of fillers. The above study also indicates that the ionic conductivity for the samples with constant loading of plasticizer is not sensitive to the loading and type of fillers.

For the second group of composite electrolytes with constant ratio (1:1) between the PEO and plasticizer, the effects of filler type and loading on ionic conductivity are displayed in Figure 4. As shown in Figure 4 (a), (b) and (c), similar curves to the first group of samples were observed. However, the ionic conductivity shows notable dependent behavior with the filler loading for each type of fillers. In specific, with the increase of the filler loading, the ionic conductivity decreases. As shown in Figure 4 (d), the ionic conductivity decreased from $1.5 \mathrm{mS} / \mathrm{cm}$ to 0.5 $\mathrm{mS} / \mathrm{cm}$ when the filler loading increased from $1 \mathrm{wt} \%$ to $20 \mathrm{wt} \%$. This result further confirms that the plasticizer is the key component controlling the ionic conductivity since the increasing 
loading of filler decreases the loading of plasticizer and so the ionic conductivity. Further, it can be found that the type of fillers has little effect on the ionic conductivity in this case, which is similar to the results shown in Figure 3. This set of samples further prove that the ionic conductivity of these composite gel electrolytes is dominated by the overall loading or volume fraction of the plasticizer, indicating that the fillers didn't interact strongly with the plasticizer and the plasticizer is distributed in the PEO matrix.

\subsection{Mechanical properties}

Good mechanical properties of electrolytes can get rid of the using of separator and potentially increase the energy/power density. Moreover, a high modulus of electrolyte is also believed effective to suppress the growth of lithium dendrites, which is the most critical issue for lithium metal batteries.[33, 34] Therefore, achieving good mechanical properties as well as high ionic conductivity has been one of the most significant tasks in composite gel electrolytes. The mechanical properties of the first group of composite electrolytes are shown in Figure 5. Figure 5 (a), (b) and (c) are the results of frequency sweep. All the samples show viscoelastic behavior, that is, the modulus is frequency-dependent. In general, the storage modulus increases with the increasing loading of the filler. Particularly, for the composite electrolyte with gelatin as the filler, the mechanical properties increase remarkably with the increasing loading. In contrast, the contribution of filler loading to the modulus for the other two type of fillers is much weaker as displayed by Figure 5 (b) and (c). For a clearer comparison, the modulus at the frequency of $5 \mathrm{~Hz}$ has been selected and compared in Figure 5 (d). In specific, the storage modulus for gelatin

reinforced composite electrolytes was increased from $2.5 \times 10^{4} \mathrm{~Pa}$ to $6.2 \times 10^{4} \mathrm{~Pa}$ when the loading increased from $0.5 \mathrm{wt} \%$ to $10 \mathrm{wt} \%$. In comparison, the reinforcement effect from wax 
particles and SPI is not significant. The notable improvement in modulus demonstrates that gelatin is a promising filler different from regular fillers to reinforce the mechanical properties.

For the second group of composite electrolytes, the mechanical properties are shown in Figure 6. Figure 6 (a)-(c) display the frequency sweep curves for the composite electrolyte with different type and loading of filler. Basically, similar results to the first group of samples were obtained. Figure 6 (d) further summary the effects of loading and type of fillers on the modulus determined at a fixed frequency $5 \mathrm{~Hz}$ as employed previously. Once again, the gelatin samples show the best performance in mechanical properties. In specific, when the filler loading increased from $1 \mathrm{wt} \%$ to $20 \mathrm{wt} \%$, the storage modulus of gelatin-reinforced composite electrolytes increased from $2.5 \times$ $10^{4} \mathrm{~Pa}$ to $1.7 \times 10^{5} \mathrm{~Pa}$. While, the modulus of SP and wax particle reinforced samples was increased from $2.5 \times 10^{4} \mathrm{~Pa}$ to about $1.2 \times 10^{5} \mathrm{~Pa}$. The notable improvement of mechanical properties for the gelatin-reinforced composite electrolyte should be related to the following factors. Firstly, as revealed by the SEM images, gelatin forms better interfaces with PEO matrix, indicating a good compatibility between them. This conclusion is further supported by the result in Figure 5d and Figure 6d, which shows a linear dependent behavior for the mechanical properties on the loading of gelatin filler. A linear dependent behavior is believed to be a good evidence that the filler phase has a good compatibility with the matrix as revealed by other studies. $[35,36]$

For the additives studied in this work, the contribution to both the ionic conductivity and modulus of the composite electrolytes for the two sample groups is summarized in Figure 7 (a) and (b). For Figure 7, there are two points worthy of discussion. The first one is the effects of filler type on electrolyte properties. It can be found that the two groups of composite electrolytes 
all show that the type of fillers has significant influence on the electrolyte properties. In particular, gelatin can notably improve the mechanical properties no matter which method was employed to control the compositions. The second one is that the trade-off between ionic conductivity and mechanical properties can be effectively adjusted by the type of filler as well as the method on controlling the compositions. Specifically, for the first group of adhesive composite electrolytes with constant loading of plasticizer (see Figure 7 (a)), the storage modulus of the gelatin-reinforced sample was improved by about 2 times as compared with the sample without any filler. While, the ionic conductivity was kept almost constant. This result indicates that the conductivity-modulus trade-off can be eliminated by a combination of high-performance filler and constant loading of plasticizer. For the adhesive samples from the second group with constant ratio between PEO and plasticizer, one can find that there is a clear conductivitymodulus trade-off, that is, the modulus decreases with the increasing of ionic conductivity, for each type of filler. In spite of this trade-off, gelatin-reinforced samples again show much better performance since the data points of gelatin-reinforced samples (see Figure 7 (b)) is on the top among all the three types of samples, which leads to higher either modulus or ionic conductivity for the gelatin-reinforced samples when compared with the others.

In addition to modulus, another type of mechanical property, that is, elasticity, further confirms that gelatin is a superior filler as compared with SPI and wax particles. To determine the elasticity, creep-recovery testing via a parallel rheometer (Hybird, TA) was employed and the elasticity can be defined as $\left(\gamma_{\mathrm{c}}-\gamma_{\mathrm{s}}\right) / \gamma_{\mathrm{c}}$, where $\gamma_{\mathrm{c}}$ is the controlled strain generated in the creep step, $\gamma_{\mathrm{s}}$ is the residual strain after the recovery process. Therefore, $\gamma_{\mathrm{c}}-\gamma_{\mathrm{s}}$ represents the recoverable strain. The creep-recovery testing results are shown by Figure 8 (a). For the first group of samples with constant loading of plasticizer, the highest elasticity $(0.73)$ was obtained by the 
gelatin-reinforced composite electrolyte as shown by Figure 8 (b). Followed by the SPIreinforced composite electrolyte and the reference without any filler (0.65), and the one with wax particles (0.60). Similar results have been achieved for the second group of samples with fixed $\mathrm{PEO} /$ plasticizer ratio, as shown in Figure 9 (a) and (b). In specific, from the samples reinforced by wax particle, SPI and gelatin, the value of the elasticity is $0.69,0.73$ and 0.76 , respectively.

\subsection{Adhesion properties}

Another significant contribution from the protein is the improvement in interfacial adhesion. As introduced before, a strong adhesion of electrolyte with electrode surface will enable stable and good contact between the electrodes and electrolyte even under deformations. In fact, interfacial issues have been one of the critical issues for non-liquid electrolytes. For the adhesive composite electrolytes, we particularly investigated the contribution of the fillers to the adhesion properties.

The results are shown in Figure 10 (a) and (b). It can be found that the adhesion strength increases with the increasing loading of gelatin and SPI, but decreases with the increasing loading of wax particles. It is noted that the improvement by gelatin is more remarkable as compared to SPI. The possible mechanism is illustrated by Figure 10 (c). It is believed that the functional groups along protein chains are responsible for the improvement in adhesion strength since they may provide various strong interactions (e.g. hydrogen bonding, van der Waals force and electrostatic forces) with the substrate.

\subsection{Battery performance studies}

To demonstrate the electrochemical and mechanical functions (electrolyte and separator) of the gelatin-CE as described above, the battery performance of a half-cell assembled with the gelatin$\mathrm{CE}$ was further studied. First, a half-cell consists of a cathode ( $\left.\mathrm{LiCoO}_{2}-\mathrm{PVDF}-\mathrm{CB}\right)$, 
electrolyte/separator (gelatin-CE) and Li-metal as anode was assembled with the configuration of coin-cell in an argon-filled glovebox. Then the coin-cell was charged and discharged via a battery analyzer with a constant current of $0.1 \mathrm{C}(0.07 \mathrm{~mA})$. The charging and discharging curves with cut-off voltages of $3-4 \mathrm{~V}$ are shown in Figure 11 (a). It can be found that the gelatin-CE works very well as a high performance electrolyte as well as a mechanical separator, which gives rise to the typical charging/discharging curves of $\mathrm{LiCoO}_{2}$. It is also noted that there is only a small voltage difference (ca. $0.04 \mathrm{~V}$ ) between the charging plateau (ca. $3.92 \mathrm{~V}$ ) and discharging plateau (ca. $3.88 \mathrm{~V}$ ). Since this voltage difference is believed the result of a polarization phenomenon in the cell, $[37,38]$ one can conclude that the gelatin-CE can remarkably reduce the polarization, which is critical to achieve high capacity as well as power density.[39] Since the polarization during charging/discharging is mainly related to the movement of anion $\left(\mathrm{ClO}_{4}{ }^{-}\right)$, it is believed that the gelation nanoparticles can help to "fix" the anion and improve the $\mathrm{Li}^{+}-$ transference number, which leads to the low polarization as described above. This low polarization also helps to improve the capacity of the $\mathrm{LiCoO}_{2}$ cathode. As shown in Figure 11 (b), a high capacity of ca. $170 \mathrm{mAh} / \mathrm{g}$ was achieved at $0.1 \mathrm{C}$, which is much higher than $\mathrm{LiCoO}_{2}$ cathode using conventional liquid electrolyte as shown Figure 11 (b).

\section{Conclusions}

In summary, we have demonstrated that natural gelatin protein is a promising bio-filler for highperformance composite electrolytes. The compatibility between the protein filler and the polymer matrix plays a critical role in contribution to the mechanical and interfacial adhesion strength of the resultant composite electrolytes as revealed by the gelatin-reinforced samples. Further, this study shows that the mechanical properties of the composite electrolytes can be notably improved by protein without sacrificing ionic conductivity, which indicates an effective way to 
solve the critical issues in gel electrolytes; that is, the trade-off between ionic conductivity and mechanical properties. Significantly, the electrochemical performance of a half-cell with the gelatin-reinforced composite electrolyte further proves that it can be used as a high-performance electrolyte material, which can reduce the polarization and improve the capacity. In a word, this study indicates that natural protein is a promising bio-filler with unique functions for advanced composite electrolytes.

\section{Acknowledgements}

The authors appreciate the financial support from "A Gum-like Multifunctional Composite for High-performance Electrolyte: Processing, Structures and Performances”, under award number NSF-1463616 and USDA 2015-67021-22911. The authors also appreciate the support on characterizations from the Franceschi Microscopy \& Imaging Center, on rheological testing from Composite Materials and Engineering Center at Washington State University.

\section{References}

[1] L.F. Chen, Z.H. Huang, H.W. Liang, W.T. Yao, Z.Y. Yu, S.H. Yu, Flexible all-solidstate high-power supercapacitor fabricated with nitrogen-doped carbon nanofiber electrode material derived from bacterial cellulose, Energy Environ. Sci. 6 (2013), 3331-3338.

[2] J.Y. Choi, D.J. Lee, Y.M. Lee, Y.G. Lee, K.M. Kim, J.K. Park, K.Y. Cho, Silicon Nanofibrils on a Flexible Current Collector for Bendable Lithium-Ion Battery Anodes, Adv. Funct. Mater. 23 (2013), 2108-2114.

[3] Y. Wang, B. Li, J. Ji, A. Eyler, W.H. Zhong, A Gum-Like Electrolyte: Safety of a Solid, Performance of a Liquid, Adv. Energy Mater. 3 (2013), 1557-1562.

[4] H. Lee, J.K. Yoo, J.H. Park, J.H. Kim, K. Kang, Y.S. Jung, A Stretchable PolymerCarbon Nanotube Composite Electrode for Flexible Lithium-Ion Batteries: Porosity Engineering by Controlled Phase Separation, Adv. Energy Mater. 2 (2012), 976-982.

[5] H. Yoo, M. Jo, B.S. Jin, H.S. Kim, J. Cho, Flexible Morphology Design of 3D- Macroporous LiMnPO4 Cathode Materials for Li Secondary Batteries: Ball to Flake, Adv. Energy Mater. 1 (2011), 347-351. 
[6] Y. Wang, W.H. Zhong, Development of Electrolytes towards Achieving Safe and High- Performance Energy- Storage Devices: A Review, ChemElectroChem. 2 (2015), 22-36.

[7] B. Scrosati, J. Hassoun, Y.K. Sun, Lithium-ion batteries. A look into the future, Energy Environ. Sci. 4 (2011), 3287-3295.

[8] J. Wen, Y. Yu, C. Chen, A review on lithium-ion batteries safety issues: existing problems and possible solutions, Mater. Express 2 (2012), 197-212.

[9] Q. Wang, P. Ping, X. Zhao, G. Chu, J. Sun, C. Chen, Thermal runaway caused fire and explosion of lithium ion battery, J.Power Sources 208 (2012), 210-224.

[10] P.G. Balakrishnan, R. Ramesh, T. Prem Kumar, safety mechanisms in lithium-ion batteries, J. Power Sources 155 (2006), 401-414.

[11] Y. Wang, B. Li, J. Ji, W.H. Zhong, Controlled Li+ conduction pathway to achieve enhanced ionic conductivity in polymer electrolytes, J. Power Sources 247(2014), 452-459.

[12] S.S. Sekhon, Conductivity behaviour of polymer gel electrolytes: Role of polymer, B. Mater. Sci. 26 (2003), 321-328.

[13] A. Manuel Stephan, Review on gel polymer electrolytes for lithium batteries, Eur. Polym. J. 42 (2006), 21-42.

[14] V.R. Basrur, J. Guo, C. Wang, S.R. Raghavan, synergistic gelation of silica nanoparticles and a sorbitol-based molecular gelator to yield highly-conductive free-standing gel electrolytes, ACS Appl. Mater. Inter. 5 (2013), 262-267.

[15] J.M. Tarascon, M. Armand, Issues and challenges facing rechargeable lithium batteries, Nature 414 (2001), 359-367.

[16] V. Etacheri, R. Marom, R. Elazari, G. Salitra, D. Aurbach, Challenges in the development of advanced Li-ion batteries: a review, Energy Environ. Sci. 4 (2011), 3243-3262.

[17] D.F. Miranda, C. Versek, M.T. Tuominen, T.P. Russell, J.J. Watkins, Cross-linked block copolymer/ionic liquid self-assembled blends for polymer gel electrolytes with high ionic conductivity and mechanical strength, Macromolecules 46 (2013), 9313-9323.

[18] H. Ye, J. Huang, J.J. Xu, A. Khalfan, S.G. Greenbaum, Li ion conducting polymer gel electrolytes based on ionic liquid/PVDF-HFP blends, J. Electrochem. Soc. 154 (2007), 10481057.

[19] C. Lee, J.H. Kim, J.Y. Bae, Polymer gel electrolytes prepared by thermal curing of poly (vinylidene fluoride)-hexafluoropropene/poly (ethylene glycol)/propylene carbonate/lithium perchlorate blends, Polymer 44 (2003), 7143-7155.

[20] J.Lee, Y. Kang, D.H. Suh, C. Lee, Ionic conductivity and electrochemical properties of cross-linked poly [siloxane-g-oligo (ethylene oxide)] gel-type polymer electrolyte, Electrochimica Acta 50 (2004), 351-356. 
[21] R.X. Dong, S.Y. Shen, H.W. Chen, C.C. Wang, P.T. Shih, C.T. Liu, et al. A novel polymer gel electrolyte for highly efficient dye-sensitized solar cells, J. Mater. Chem. A 1 (2013), 8471-8478.

[22] E.H. Kil, K.H. Choi, H.J. Ha, S. Xu, J.A. Rogers, M.R. Kim, Y.G. Lee, K.M. Kim, K.Y. Cho, S.Y. Lee, Imprintable, Bendable, and Shape- Conformable Polymer Electrolytes for Versatile- Shaped Lithium- Ion Batteries, Adv. Mater. 25 (2013), 1395-1400.

[23] Y. Li, P.S. Fedkiw, Nanocomposite gel electrolytes based on fumed silica for lithium-ion batteries, J. Electrochem. Soc. 154 (2007), A1140.

[24] Y. Wang, W.H. Zhong, T. Schiff, A. Eyler, B. Li, A Particle- Controlled, High- Performance, Gum- Like Electrolyte for Safe and Flexible Energy Storage Devices, Adv. Energy Mater. 5 (2015), 1400463, doi: 10.1002/aenm.201400463.

[25] Y. Gu, S. Zhang, L. Martinetti, K.H. Lee, L.D. McIntosh, C.D. Frisbie, T.P. Lodge, J. Am. Chem. Soc. 135 (2013), 9652-9655.

[26] M. Wachtler, D. Ostrovskii, P. Jacobsson, B. Scrosati, High toughness, high conductivity ion gels by sequential triblock copolymer self-assembly and chemical cross-linking, Electrochimica Acta 50 (2004), 357-361.

[27] X. Xu, Z. Fan, S. Ding, D. Yu, Y. Du, Fabrication of $\mathrm{MoS}_{2}$ nanosheet@ $\mathrm{TiO}_{2}$ nanotube hybrid nanostructures for lithium storage, Nanoscale 6 (2014), 5245-5250.

[28] J. Xu, H. Ye, Polymer gel electrolytes based on oligomeric polyether/cross-linked PMMA blends prepared via in situ polymerization, Electrochem. Commun. 7 (2005), 829-835.

[29] Q. Lu, J. Fang, J. Yang, R. Miao, J. Wang, Y.J. Nuli, Novel cross-linked copolymer gel electrolyte supported by hydrophilic polytetrafluoroethylene for rechargeable lithium batteries, Membrane Sci. 449 (2014), 176-183.

[30] Y.H. Liao, X.P. Li, C.H. Fu, R. Xu, L. Zhou, C.L. Tan, S.J. Hu, W.S. Li, Polypropylenesupported and nano- $\mathrm{Al}_{2} \mathrm{O}_{3}$ doped poly (ethylene oxide)-poly (vinylidene fluoridehexafluoropropylene)-based gel electrolyte for lithium ion batteries, J. Power Sources, 196 (2011), 2115-2121.

[31] C. Yang, H. Wei, L. Guan, J. Guo, Y. Wang, X. Yan, X. Zhang, S. Wei, Z. Guo, Polymer nanocomposites for energy storage, energy saving, and anticorrosion, J. Mater. Chem. A 3 (2015), 14929-14941.

[32] X.W. Fu, Y. Jewel, Y. Wang, J. Liu, W.H. Zhong, Decoupled ion transport in a proteinbased solid ion conductor, J. Phys. Chem. Lett. 2016, DOI: 10.1021/acs.jpclett.6b02071. In press.

[33] D. Bresser, S. Passerini, B. Scrosati, Recent progress and remaining challenges in sulfurbased lithium secondary batteries-a review, Chemical communications 49 (2013), 10545-10562.

[34] J.T. Vaughey, G. Liu, J.G. Zhang, Stabilizing the surface of lithium metal, MRS Bulletin 39 (2014), 429-435. 
[35] R. Strapasson, S.C. Amico, M.F.R. Pereira, T.H.D. Sydenstricker, Tensile and impact behavior of polypropylene/low density polyethylene blends, Polymer testing, 24(2005), 468-473.

[36] P. Lodha, A.N. Netravali, Characterization of interfacial and mechanical properties of "green" composites with soy protein isolate and ramie fiber, J. Mater. Sci. 37(2002), 3657-3665.

[37] S.H. Wang, S.S. Hou, P.L. Kuo, H. Teng, Poly (ethylene oxide)-co-poly (propylene oxide)-based gel electrolyte with high ionic conductivity and mechanical integrity for lithium-ion batteries, ACS Appl. Mater. Interfaces 5 (2013), 8477-8485.

[38] S.P. Sheu, C.Y. Yao, J.M. Chen, Y.C. Chiou, Influence of the $\mathrm{LiCoO}_{2}$ particle size on the performance of lithium-ion batteries, J. Power Sources 68 (1997), 533-535.

[39] M. Doyle, T.F. Fuller, Newman, The importance of the lithium ion transference number in lithium/polymer cells, J. Electrochim. Acta 39 (1994), 2073-2081. 
(a)

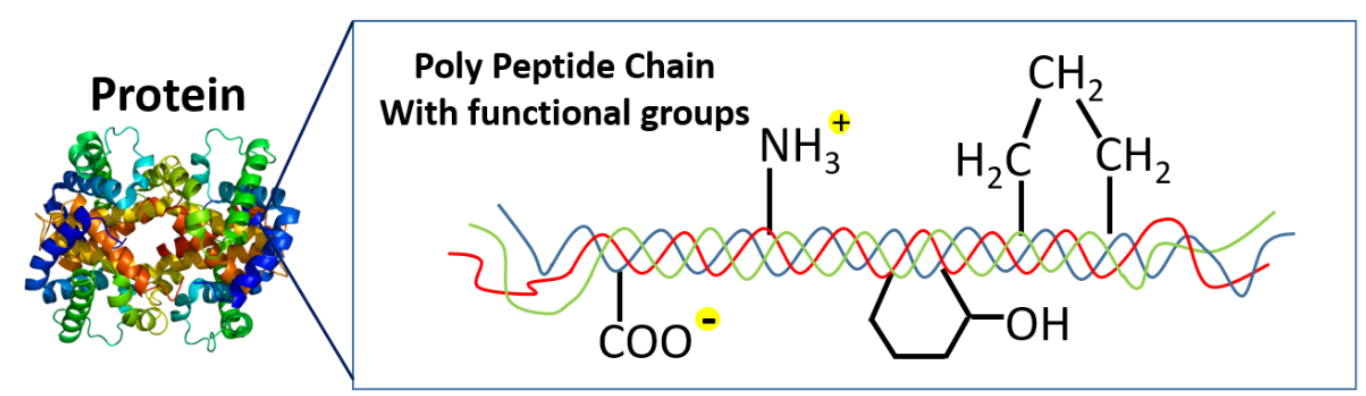

(b) Improve mechanical properties by physical crosslinking

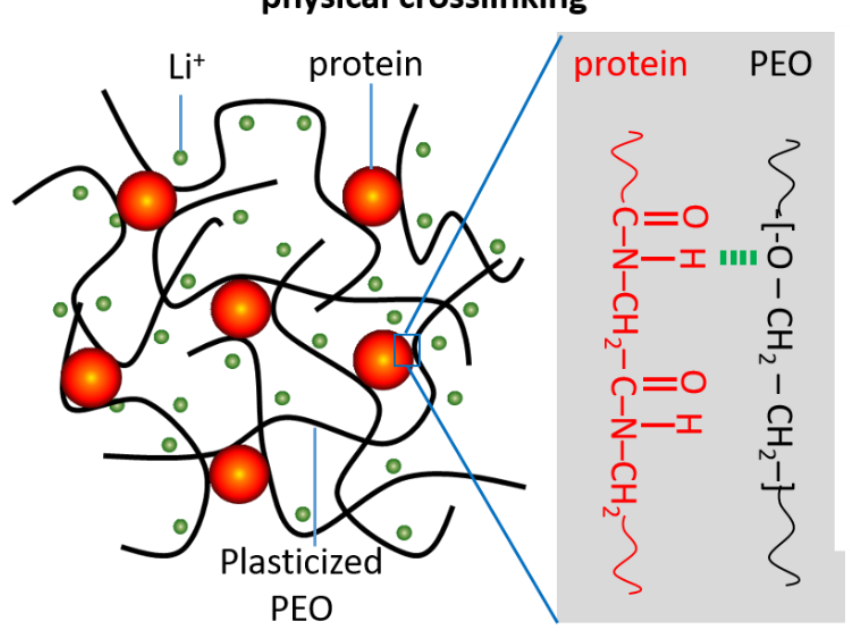

(c) Improve adhesive properties

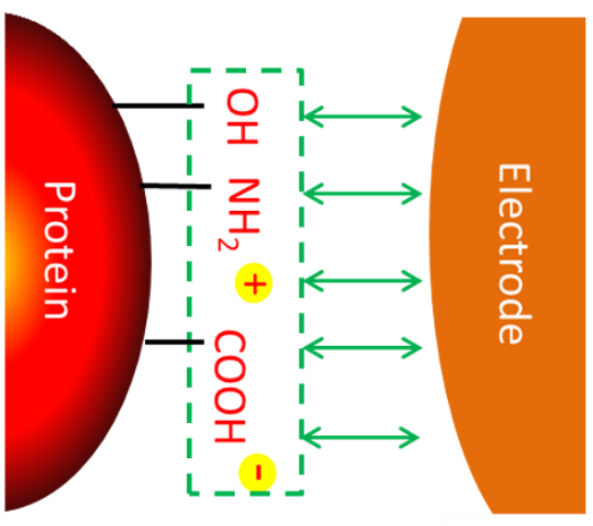

Figure 1. Protein as organic and functional bio-filler for adhesive composite electrolytes. (a)

Schematic of the structures of protein with functional groups; (b) and (c), Schematics showing the significant contribution of the functional groups of protein to the mechanical and adhesion properties of electrolyte materials, respectively. 

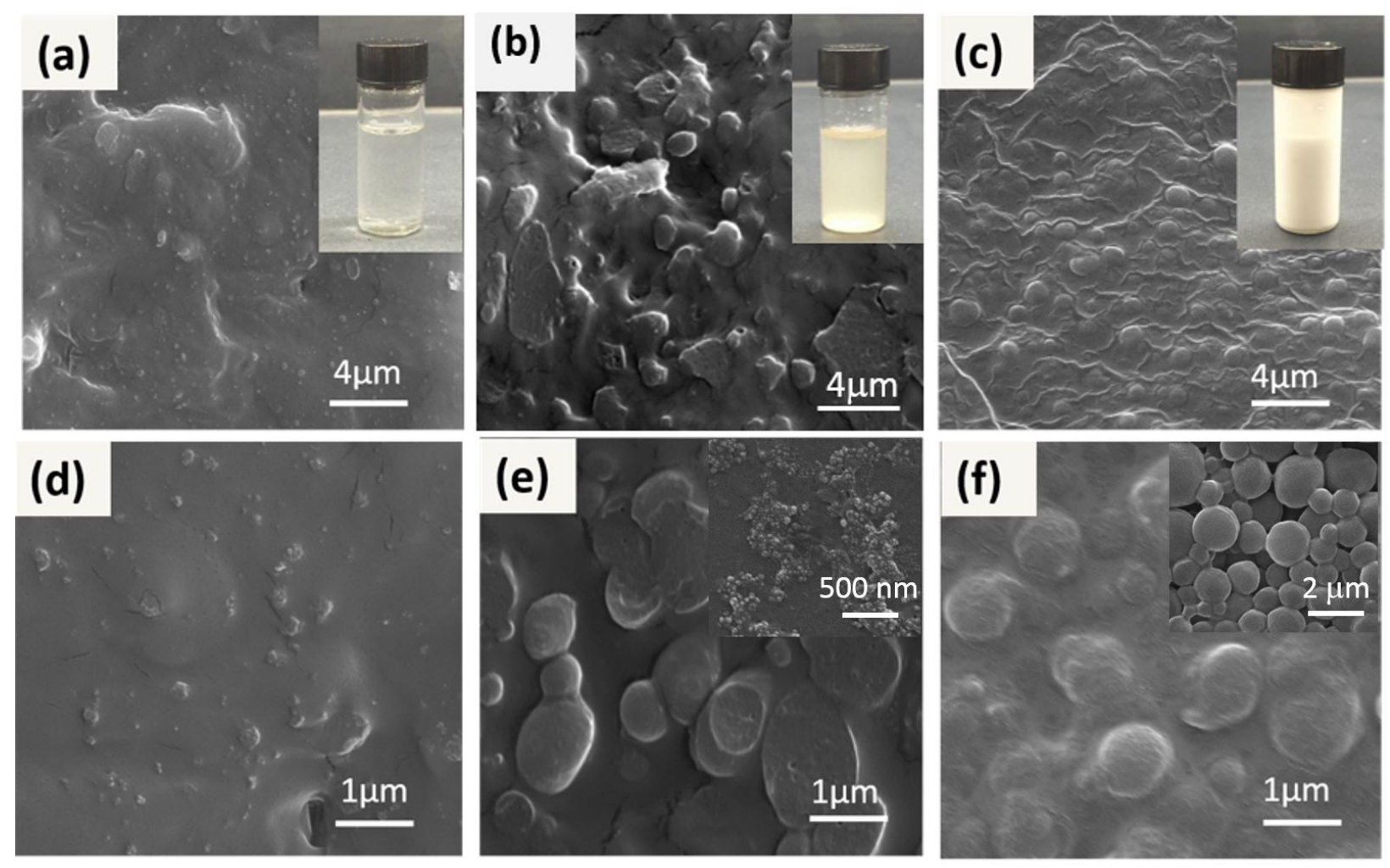

Figure 2. SEM images of the fracture surface of the adhesive composite electrolytes with different fillers. The loading of filler for all the samples is $10 \mathrm{wt} \%$. From (a) to (c), the filler is gelatin, SPI, wax particle, respectively. (d) to (e) are the SEM images with higher magnification for the samples shown by (a) to (c), respectively. The insets in (a) to (c) are the corresponding solutions/suspensions of gelatin, SPI and wax particles in DI water before mixing with PEO solution. The insets in (e) and (f) are the SEM images of the corresponding original particles before mixing with the polymer matrix. 

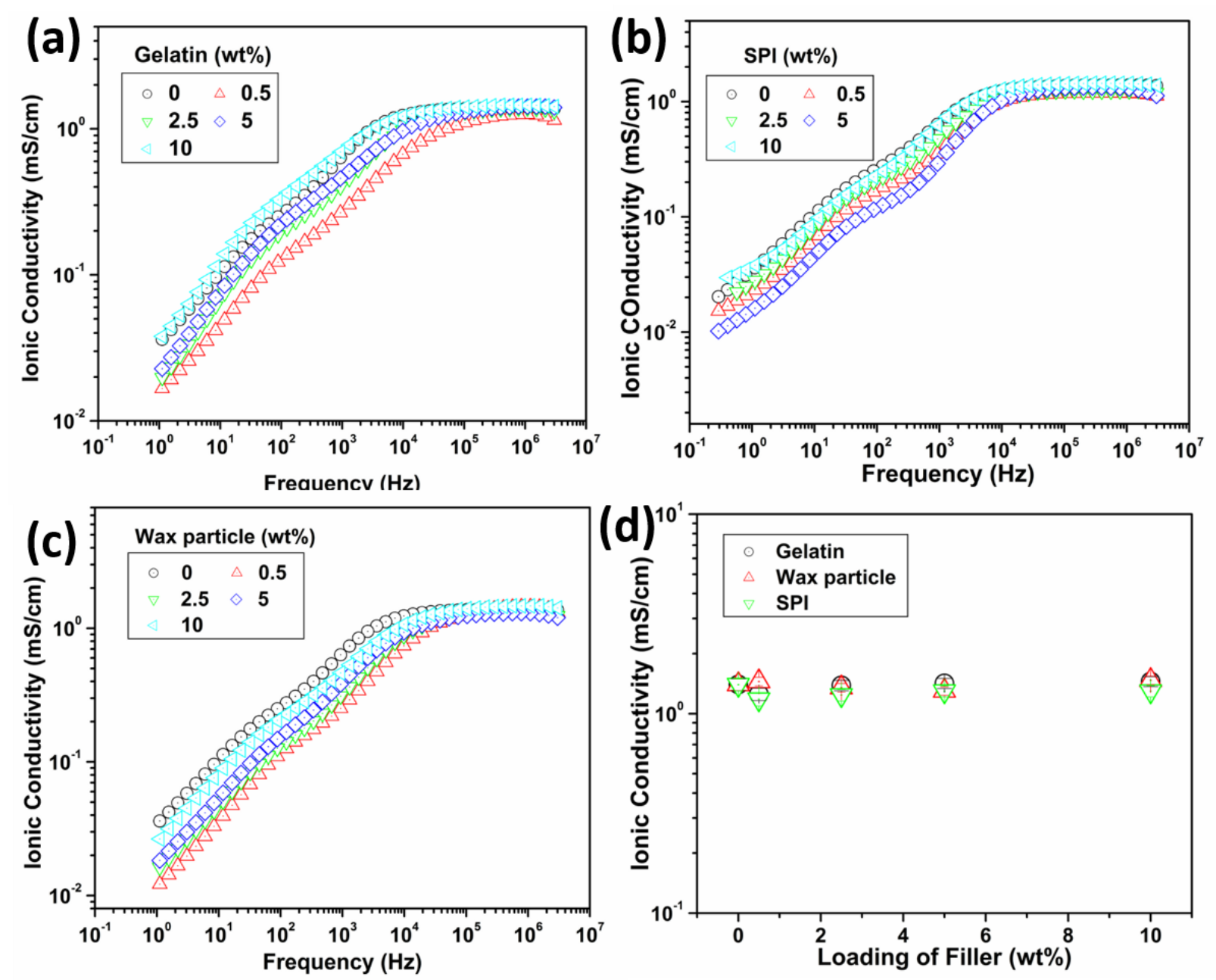

Figure 3. Ionic conductivity of the adhesive composite electrolytes from the first group with a constant plasticizer loading of $50 \mathrm{wt} \%$. Ionic conductivity vs. frequency for the composite electrolytes with gelatin particles (a), wax particles (b) and SPI (c). (d) Effects of the filler on the ionic conductivity. 

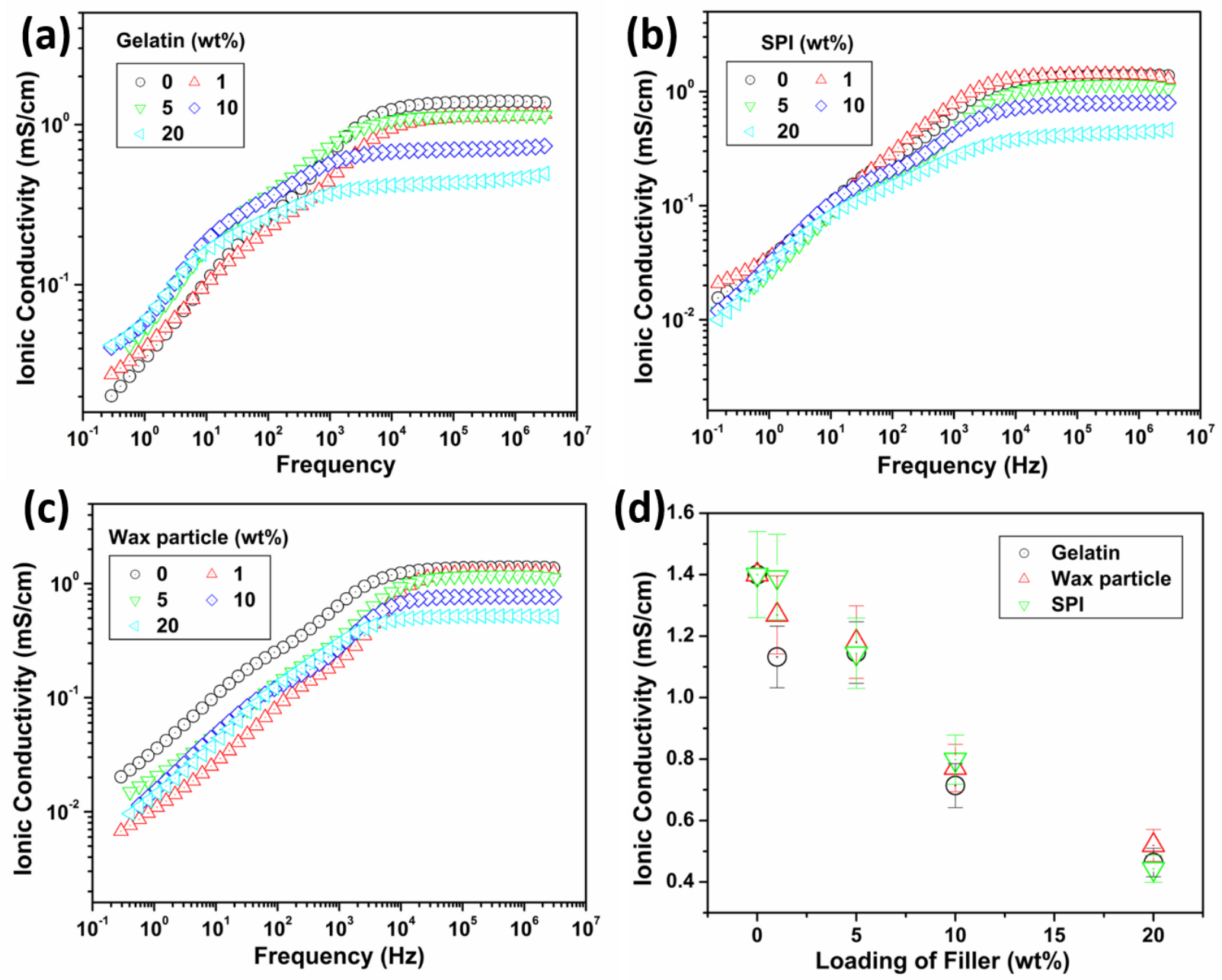

Figure 4. Ionic conductivity of the adhesive composite electrolytes from the second group with a fixed PEO-plasticizer ratio (1:1). Ionic conductivity vs. frequency for the composite electrolytes with gelatin particles (a), wax particles (b) and SPI (c). (d) Effect of the filler loading on the ionic conductivity. For all the composite electrolytes, the ratio between PEO-LiClO4 and plasticizer was kept constant 1:1. 

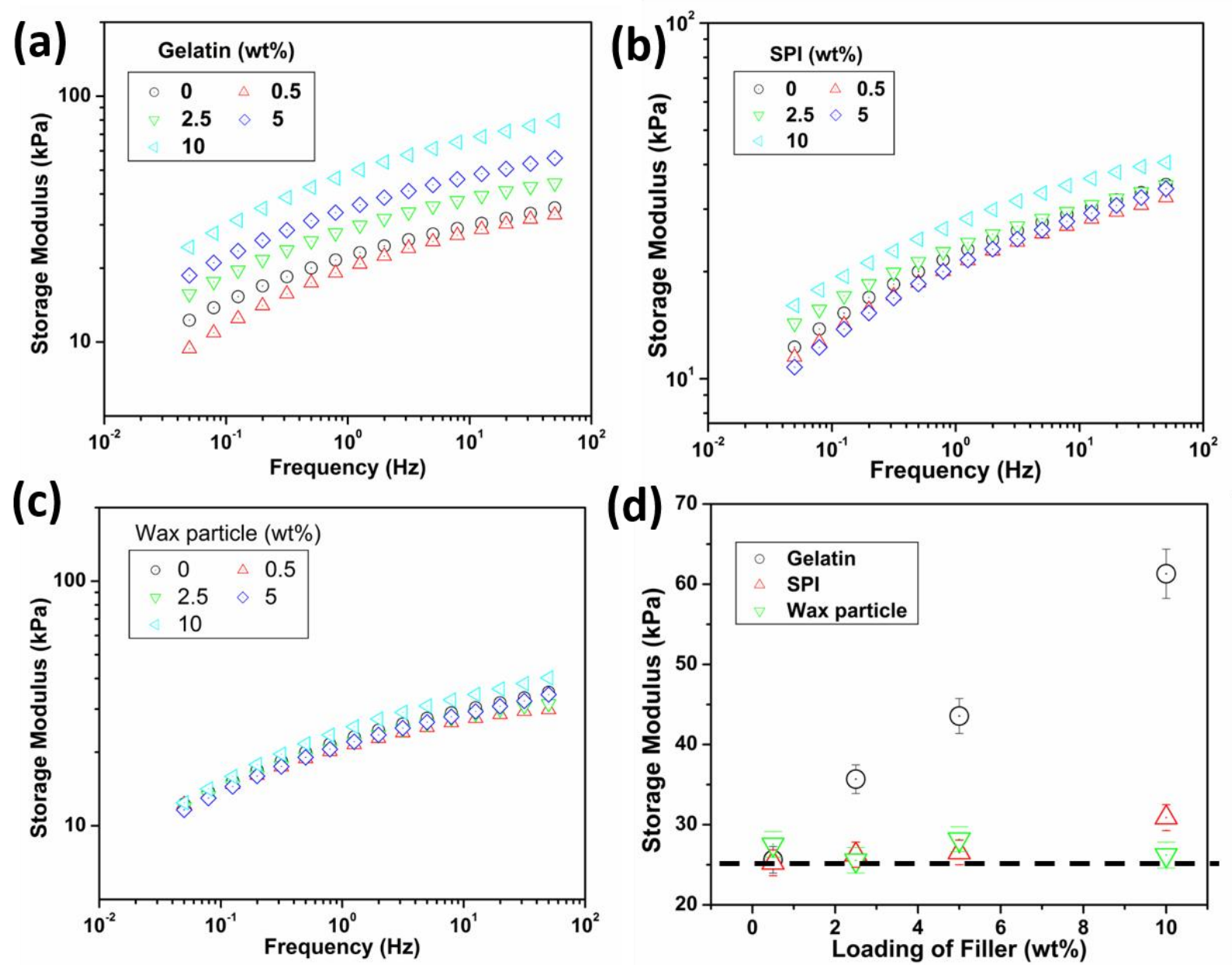

Figure 5. Mechanical properties of the adhesive composite electrolytes from the first group. Frequency-dependent behaviors of the modulus with different loading of (a), gelatin, (b), SPI and (c) wax particles; (d) Comparison of the storage modulus (at a frequency of $5 \mathrm{~Hz}$ ) for the electrolytes with gelatin, wax particles and SPI as the fillers; The dashed line in (d) represents the value of filler-free adhesive electrolyte with $50 \mathrm{wt} \%$ plasticizer. The LEs loading was kept constant $50 \%$ for all the samples. 

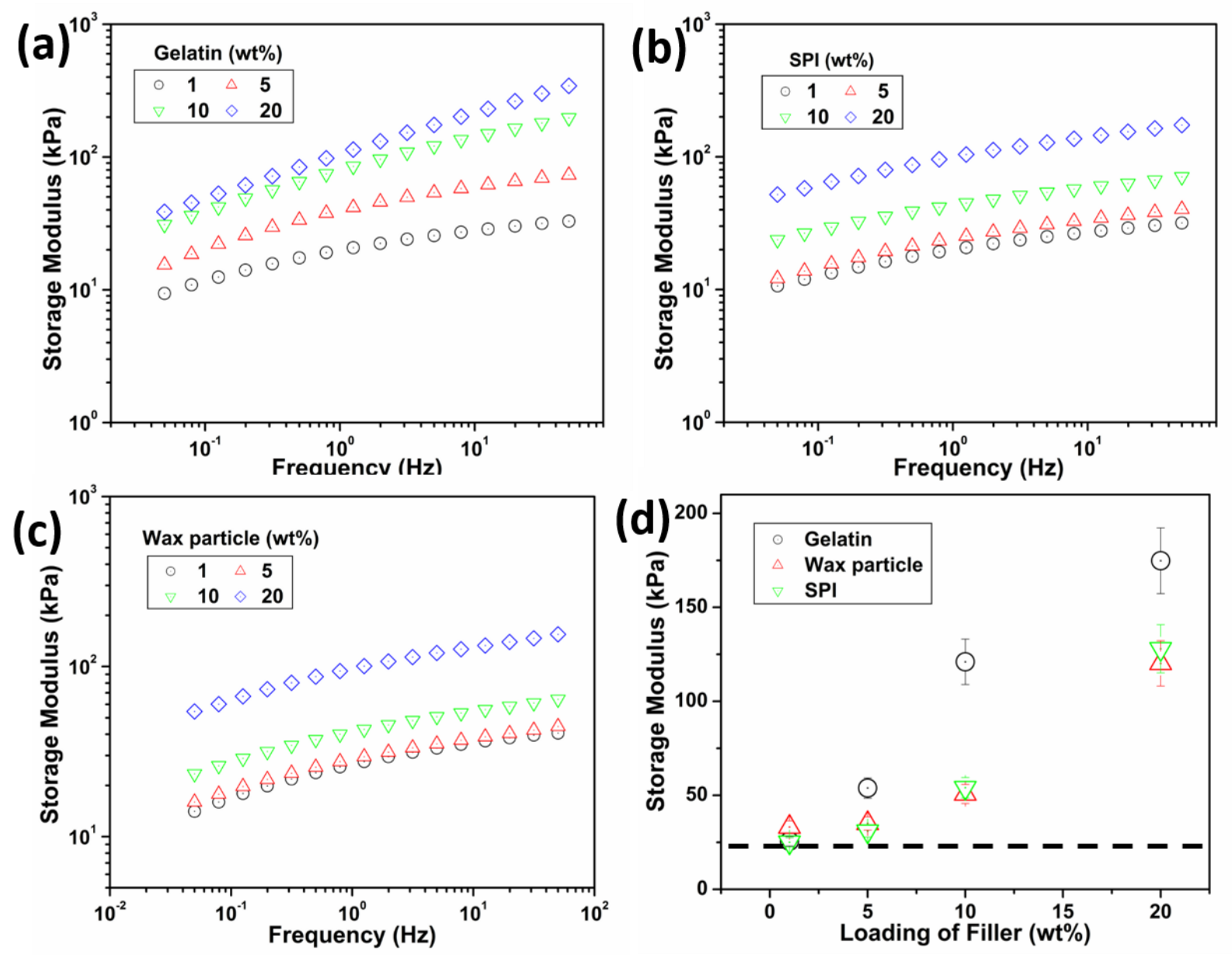

Figure 6. Mechanical properties of the adhesive composite electrolytes from the second group. Frequency-dependent behaviors of the modulus with different loading of (a), gelatin, (b), SPI and (c) wax particles; (d) Comparison of the storage modulus (at a frequency of 5Hz) for the electrolytes with gelatin, wax particles and SPI as the fillers. The dashed line in (d) represents the value of filler-free adhesive electrolyte with $50 \mathrm{wt} \%$ plasticizer. The ratio between PEO and matrix was kept constant 1:1 for all the samples. 

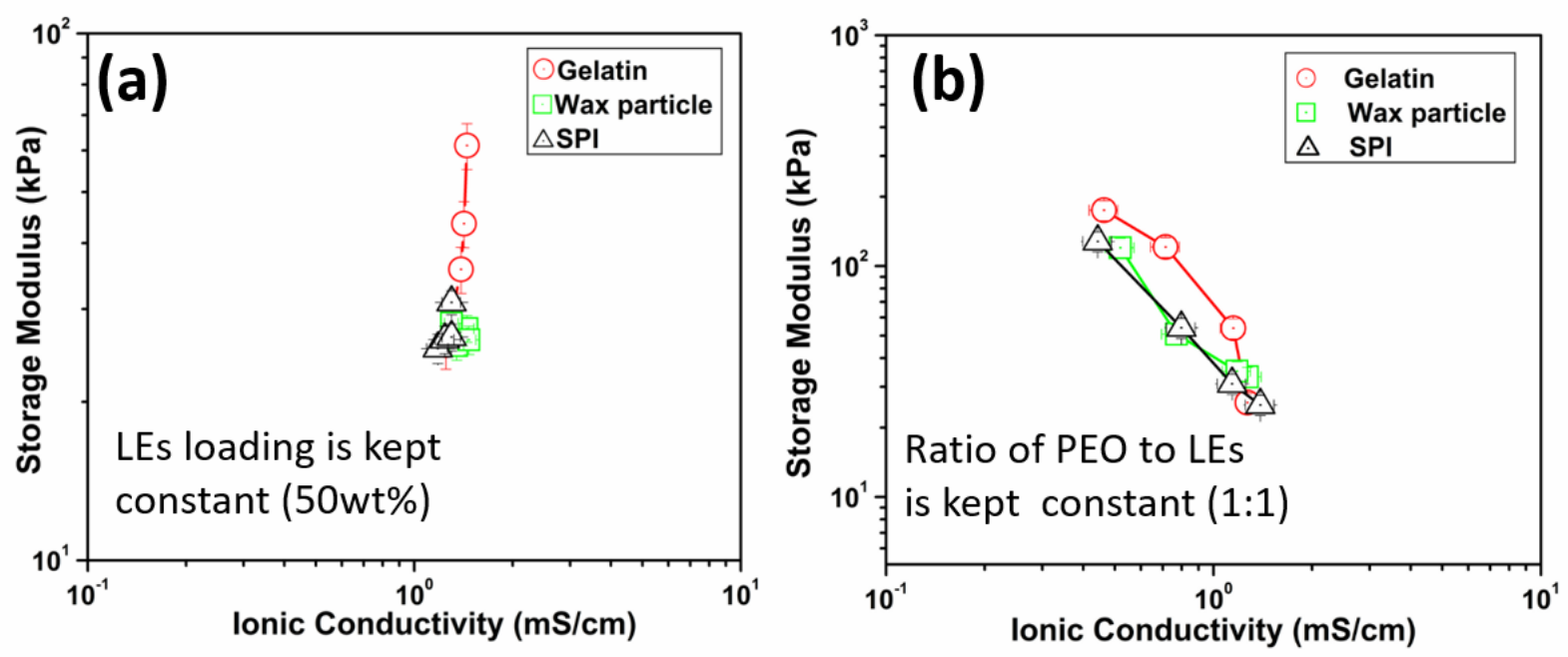

Figure 7. Modulus vs Ionic conductivity plot for the adhesive composite electrolytes from the first group with constant loading of $50 \mathrm{wt} \%$ plasticizer (a), and the second group with fixed ratio between PEO and plasticizer, (b).
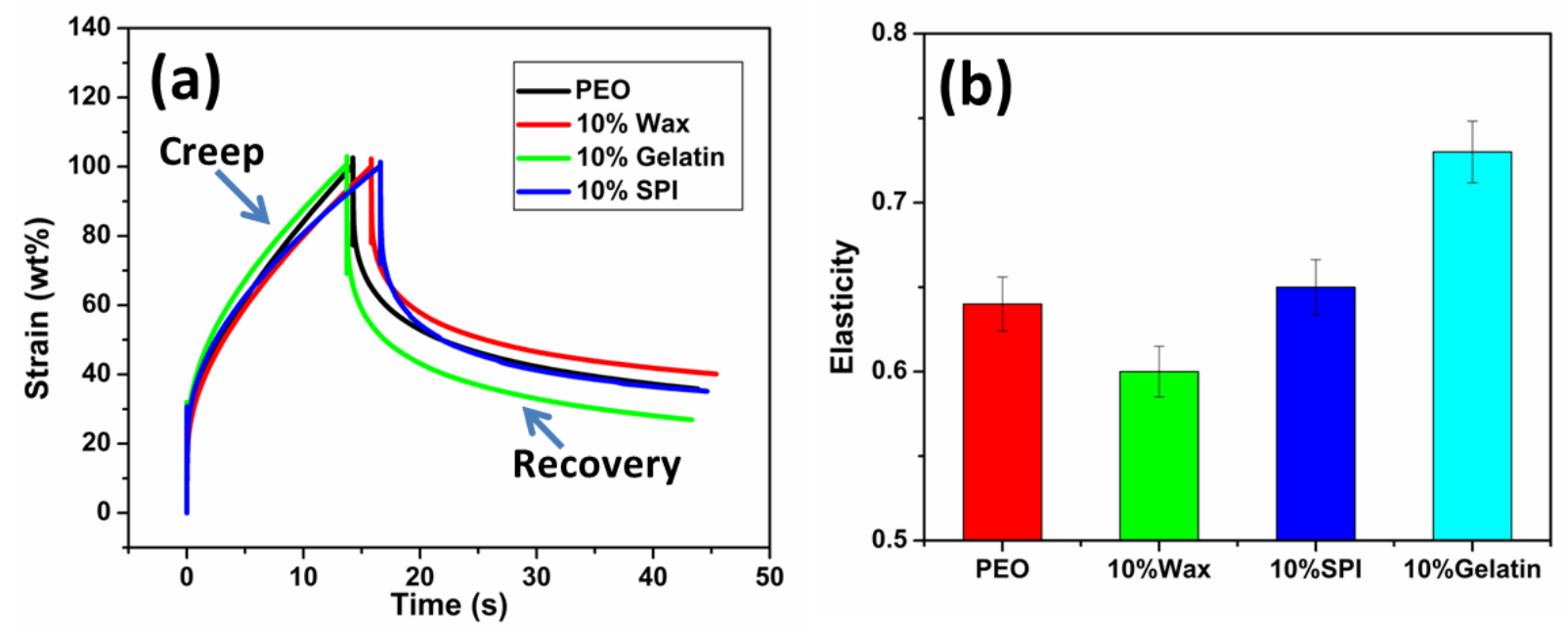

Figure 8. Effects of filler type on the elasticity of the composite electrolytes for the first group of samples with constant loading of plasticizer: (a) creep and recovery testing curves, (b) comparison of the elasticity. The filler loading is $10 \mathrm{wt} \%$ for all the composite electrolytes. 

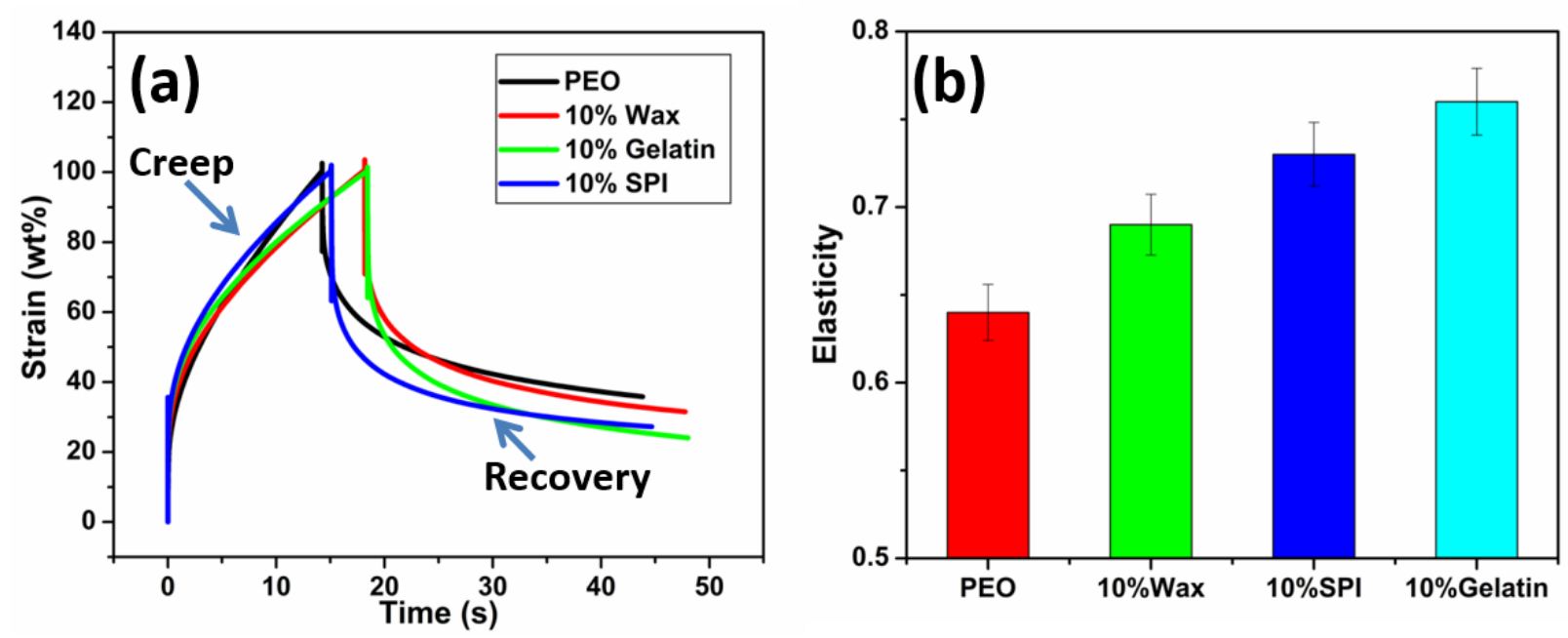

Figure 9. Effects of filler type on the elasticity of the composite electrolytes for the second group of samples with constant PEO/plasticizer ratio: (a) creep and recovery testing curves, (b) comparison of the elasticity. The filler loading is $10 \mathrm{wt} \%$ for all the composite electrolytes.
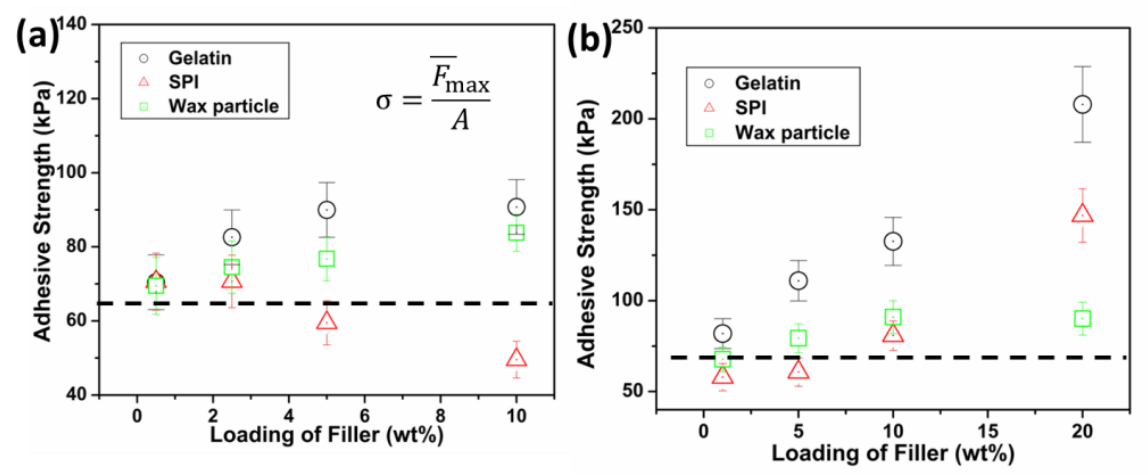

(c)

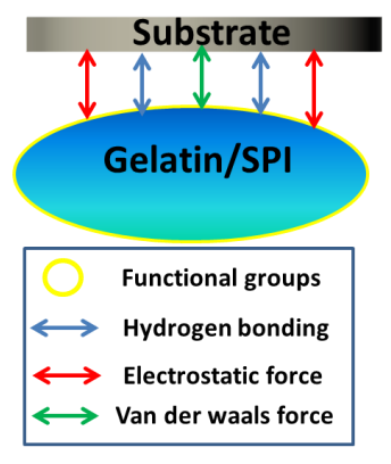

Figure 10. Adhesion properties for the composite electrolytes. (a) The adhesion strength of the samples from the first group with constant plasticizer loading (50 wt\%). (b), the adhesion strength for the samples from the second group with constant PEO/plasticizer ratio (1:1), (c) schematic of the possible mechanism for interfacial contribution from protein filler. The dashed lines in (b) and (c) represent the value of filler-free electrolyte with $50 \mathrm{wt} \%$ plasticizer. 

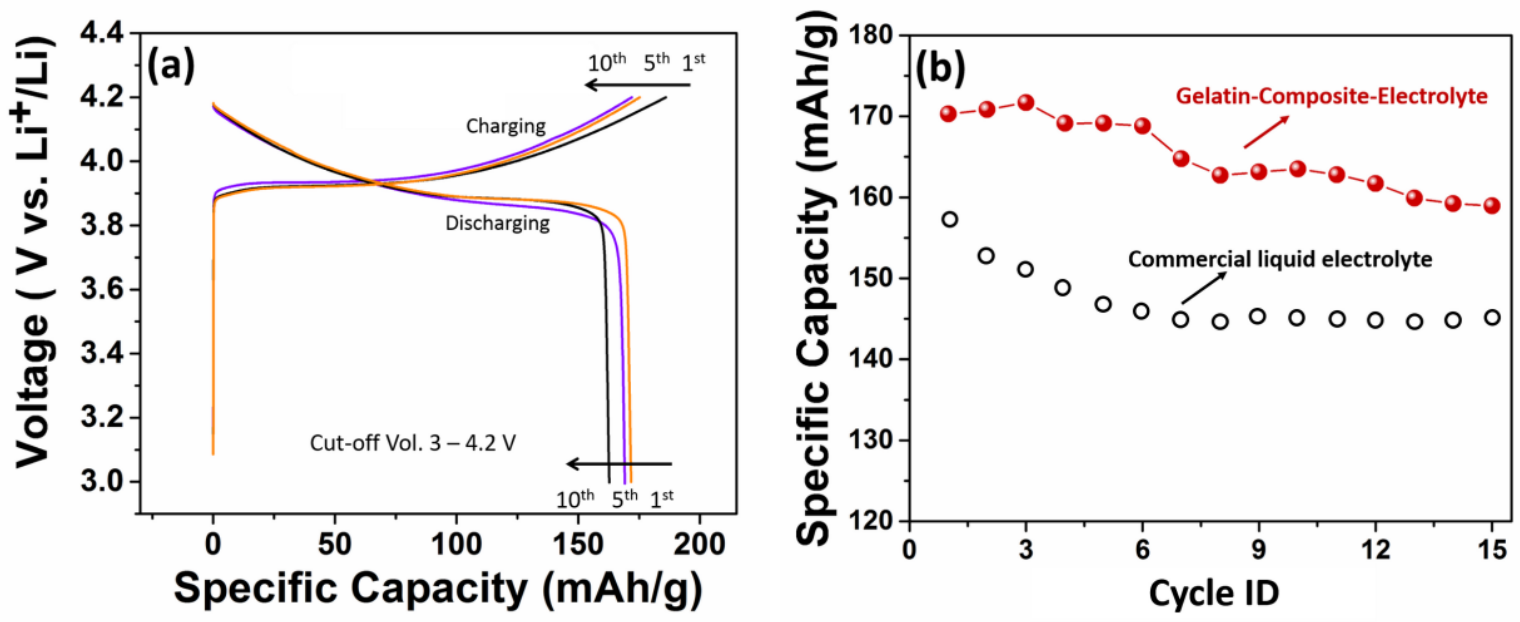

Figure 11. Electrochemical performance of the $\mathrm{Li} / \mathrm{Gelatin}-\mathrm{CE} / \mathrm{LiCoO}_{2}$ half-cell. (a) Charging/discharging curves at different cycle number, (b) Cycle performance as compared with traditional half-assembled with liquid electrolyte, $\mathrm{Li} / \mathrm{OLE}-\mathrm{Separator} / \mathrm{LiCoO}_{2}$. 

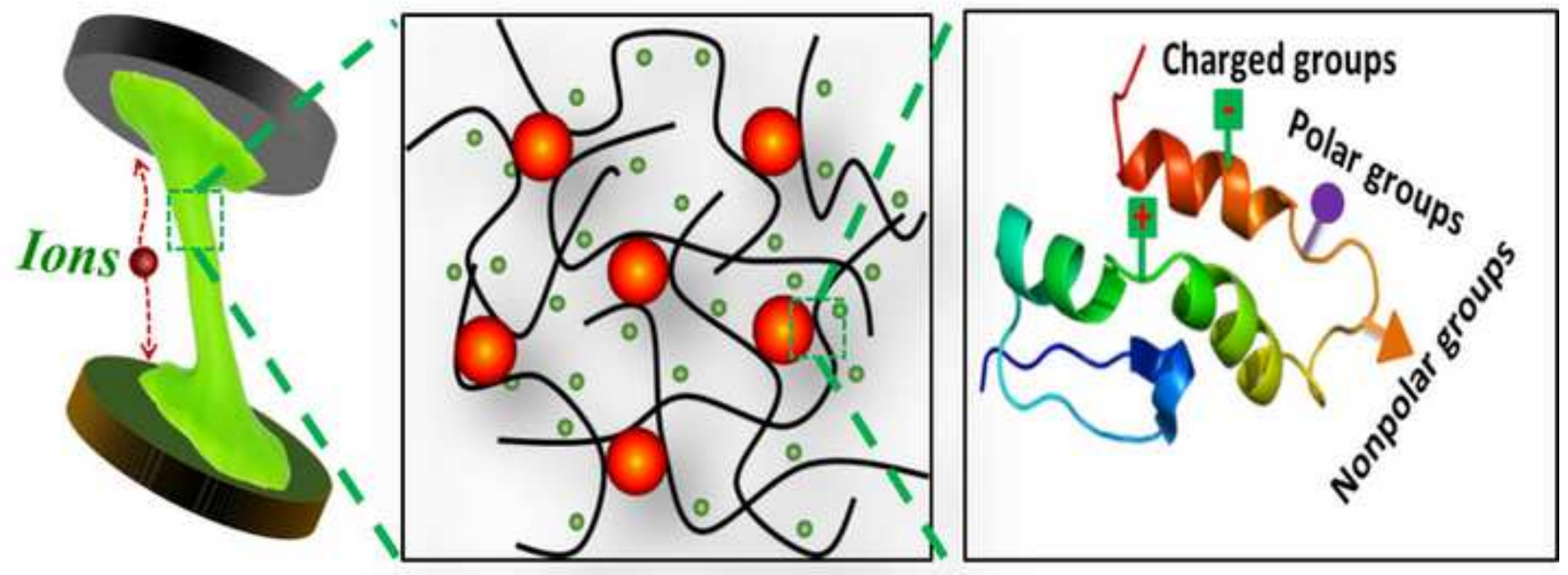